\title{
Factors Affecting Rural Patients' Primary Compliance with e-Prescription: A Developing Country Perspective
}

\author{
Nazmul Hossain, MBA, ${ }^{1,2}$ Masuda Begum Sampa, MSc, ${ }^{1}$ \\ Fumihiko Yokota, PhD, ${ }^{3}$ Akira Fukuda, $P h D,{ }^{1}$ and \\ Ashir Ahmed, $\mathrm{PhD}^{1}$ \\ ${ }^{1}$ Department of Advanced Information Technology, Kyushu \\ University, Fukuoka, Japan. \\ ${ }^{2}$ Department of Marketing, University of Dhaka, Dhaka, \\ Bangladesh. \\ ${ }^{3}$ Institute of Decision Science for Sustainable Society (IDS3), \\ Kyushu University, Fukuoka, Japan.
}

\section{Abstract}

Background: The electronic prescription system has emerged to reduce the ambiguity and misunderstanding associated with handwritten prescriptions. The opportunities and challenges of e-prescription system, its impact on reducing medication error, and improving patient's safety have been widely studied. However, not enough studies were conducted to explore and quantify the factors that affect rural patients' compliance with eprescription, especially from the perspective of Asian developing countries where most of the world's population resides.

Objective: The objective of this study is to explore and assess the factors that affect rural patients' primary compliance with e-prescription in Bangladesh.

Methods: Data were collected from 95 randomly selected rural patients who received e-prescription through a field survey with a structured questionnaire from Bheramara subdistrict, Bangladesh, during June and July 2016. Logistic regression analysis was performed to test the research hypotheses.

Results: The study found patients' gender as the most significantly influential factor (regression coefficient [Coef.] = 2.02 , odds ratio $[O R]=7.51, \mathrm{p}<0.05)$ followed by visiting frequency (Coef. $=0.99, \quad O R=2.70, \mathrm{p}<0.05)$; education (Coef. $=0.92, O R=2.51, \mathrm{p}<0.05)$; and distance to healthcare facility (Coef. $=0.82$, OR $=2.26, \mathrm{p}<0.01)$. However, patients' age, monthly family expenditure, and use of cell phone were found insignificant. The model explains 59.40\% deviance
$\left(\mathrm{R}^{2}=0.5940\right)$ in the response variable with its constructs. And the "Hosmer-Lemeshow" goodness-of-fit score (0.99) is also above the standard threshold (0.05), which indicates the data fit well with the model.

Conclusions: The findings of this study are expected to be helpful for e-health service providers to gain a better understanding of the factors that influence their patients to comply with e-prescriptions.

Keywords: e-prescription, primary compliance, rural patients, Bangladesh

\section{Introduction}

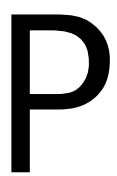

atients' noncompliance with prescription is a multifaceted healthcare problem. The reasons may be associated with the patient, treatment, and/or healthcare provider. However, as a result, patients are facing undesirable clinical outcomes and are deprived of optimal health recovery, which, in turn, lead to increased morbidity as well as increased financial and societal costs. ${ }^{1}$ In healthcare, the phrase "compliance with prescription" has a broader dimension. Vrijens et al. defined compliance as the degree to which a patient is able to follow the guidelines of prescribed treatment. ${ }^{2}$ Patients may be noncompliant in any phase of their treatment. They may decide not to collect their medicines from the pharmacy and not to start their treatment at all, which is considered as primary noncompliance. They may take more or less medication than was prescribed or use their medication at a wrong time. They may also suspend or even terminate their treatment ahead of prescribed time., ${ }^{3,4}$ This study, however, focuses on the factors that affect rural patients' primary noncompliance with e-prescription issued by a human-assisted remote healthcare system, namely Portable Health Clinic (PHC) in Bangladesh.

\section{ABOUT PHC}

PHC is an e-health initiative, jointly developed by Kyushu University, Japan, and Grameen Communications, Bangladesh,

(C) Nazmul Hossain et al. 2018; Published by Mary Ann Liebert, Inc. This Open Access article is distributed under the terms of the Creative Commons License (http://creativecommons.org/licenses/by/4.0), which permits unrestricted use, distribution, and reproduction in any medium, provided the original work is properly cited. 


\section{HOSSAIN ET AL.}

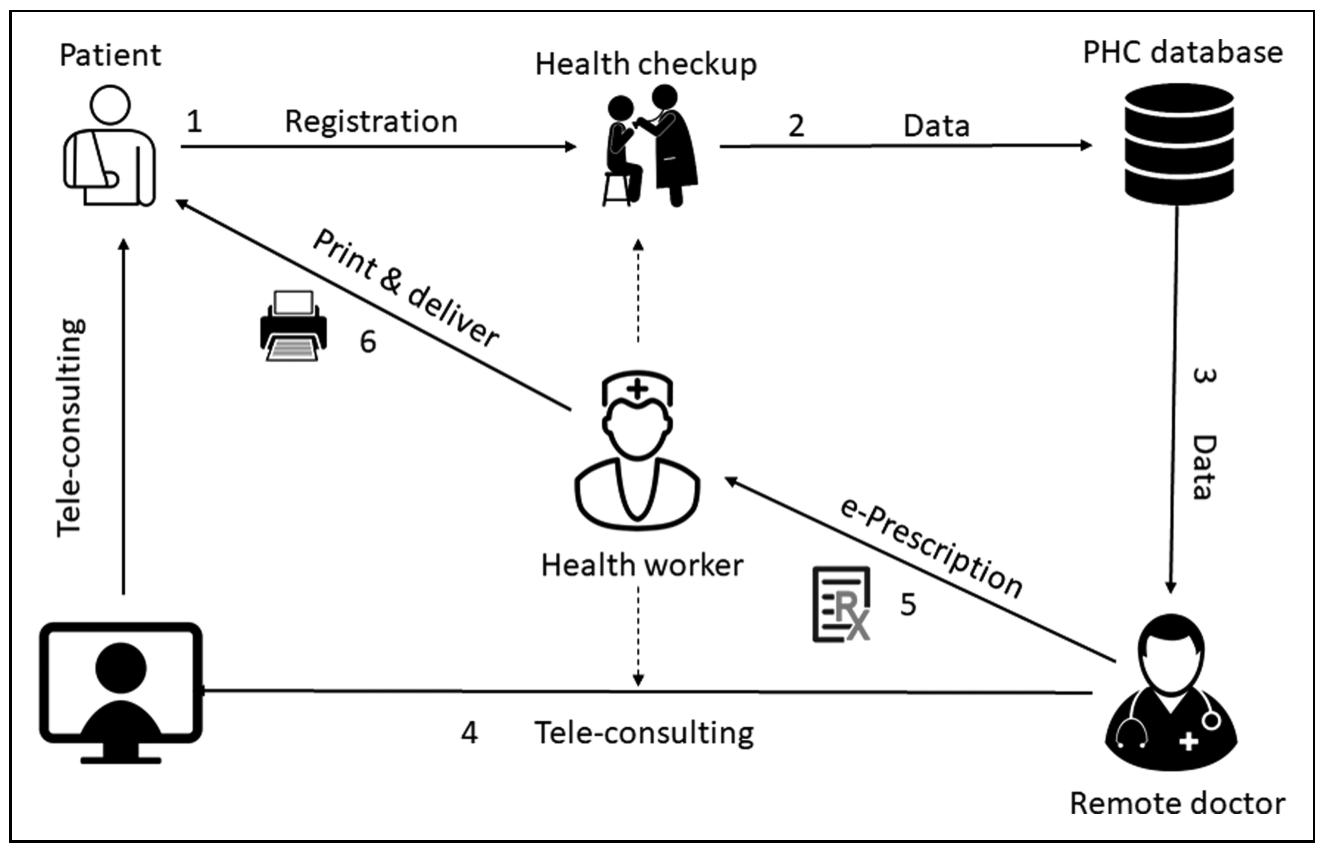

Fig. 1. Healthcare service delivery flowchart of PHC. PHC, Portable Health Clinic. lected Bheramara subdistrict of Kushtia as our data collection site, which is one of the mentioned nine districts located in the northwestern part of Bangladesh. PHC started serving in Bheramara from 2012 and has served 4,701 rural patients until the mentioned date.

\section{PHC E-PRESCRIPTION}

Handwritten prescriptions have been used as a primary means of communication between prescribers and pharmacists. Over time, the risks associated with handwritten prescriptions such as difficulties with legibility and risk of misinterpretation encouraged the adoption of electronic prescriptions. ${ }^{8}$ An e-prescribing system sends an accurate, error-free, to provide affordable healthcare solutions to low-income and low-literate people living in remote and underserved communities in Bangladesh by using information and communication technologies. $^{5,6}$

To get healthcare services from PHC, patients first have to register their vital information such as name, age, sex, location, and disease complaints with the PHC system that generates a unique patient ID. Second, health checkup is conducted with an assistance of a healthcare worker and checkup data are automatically sent and stored to the central PHC server. The next step is teleconsultancy (voice and video) between the patients in need and the remote doctor located in the headquarters of PHC. After having conversation with patients and analyzing their clinical data, if necessary the doctor might issue an eprescription, a printed version of that e-prescription is finally handed to the patient. The overall healthcare service delivery process of PHC is shown in Figure 1.

PHC is designed and targeted to provide the basic healthcare services to the underserved rural communities in Bangladesh with a view to reducing morbidity by combating against noncommunicable diseases. Therefore, majority of its patients are coming with health issues such as hypertension, anemia, arrhythmia, lower back pain, knee joint pain, burning sensation, and diabetes. PHC has started its experimental service since 2010. Until January 31, 2018, it reached 32 remote locations in 9 districts and served 41,240 rural patients, among whom 55.2\% were male and 44.8\% were female. ${ }^{7}$ For our research, we se- and understandable digital prescription directly to the patients or partnered pharmacies. It reduces the likelihood of adverse drug effects caused due to errors and misunderstandings in handwritten prescriptions. ${ }^{9}$ In Bangladesh, most of the rural patients are familiar and habituated with conventional handwritten prescriptions, whereas $\mathrm{PHC}$ is providing e-prescriptions issued by a remote doctor by using an e-prescription system software. A comparison between conventional handwritten prescription and PHC's e-prescription is given in Table 1.

According to a report by the Systems for Improved Access to Pharmaceuticals and Services (SIAPS) 2015, Bangladesh has $\sim 103,451$ licensed retail drugstores and an estimated approximately equal number of unlicensed stores are involved in selling drugs "over-the-counter." A majority (68\%) of the clients visiting the drug shops came by self-referral and without a prescription, whereas the rest came with a prescription. Dispensing drugs on the basis of a patient's request $(83 \%)$ or a patient's symptoms of illness (59\%) is quite common. ${ }^{10}$ However, as an experimental remote healthcare service provider, PHC has not yet incorporated partner pharmacies with its system, that is, prescriptions are not routed to the pharmacists, rather a printed version is handed over to the patient. It, thus, cannot monitor patients' medication progress.

\section{Background and Objective}

The features, benefits, and challenges of the e-prescription system, its impact on reducing medication error, and improving 


\section{E-PRESCRIPTION COMPLIANCE IN RURAL BANGLADESH}

\begin{tabular}{|c|c|c|}
\hline FEATURE & $\begin{array}{l}\text { HANDWRITTEN } \\
\text { PRESCRIPTION }\end{array}$ & $\begin{array}{c}\text { PHC } \\
\text { E-PRESCRIPTION }\end{array}$ \\
\hline Electronic entry & $\times$ & レ \\
\hline Address individual patient & $\nu$ & $\nu$ \\
\hline Medication monitoring & $x$ & $x$ \\
\hline Access to patient's history & $x$ & $\boldsymbol{\nu}$ \\
\hline Connect to pharmacy & $\times$ & $x$ \\
\hline $\begin{array}{l}\text { Integrate with electronic } \\
\text { medical record }\end{array}$ & $x$ & $\boldsymbol{\nu}$ \\
\hline
\end{tabular}

PHC, Portable Health Clinic.

patient's safety and overall care quality have been widely studied. Odukoya and Chui. ${ }^{11}$ explained how e-prescribing can enhance the safety of patients, physicians, and pharmacists. Jariwala et al. ${ }^{12}$ described the factors affecting the adoption of the e-prescribing system by primary care physicians and their experience with the system in the United States. Kaushal et al. ${ }^{13}$ found that e-prescriptions reduce a significant amount of prescribing errors in comparison with handwritten prescriptions. Fernando et al. ${ }^{14}$ studied how electronically delivered prescriptions reduced pharmacy waiting time and improved patient satisfaction. Lapane et al. ${ }^{15}$ measured the perception and readiness to accept electronic prescriptions among elderly geriatric patients in six states in the United States. Smith ${ }^{16}$ explored the barriers to accepting e-prescription among general patients in the Pittsburgh metropolitan area in the United States. Kierkegaard ${ }^{9}$ examined the prospects and problems concerning the cross-border use of e-prescription among 27 member countries of the European Union. Ateniese and de Medeiros ${ }^{17}$ studied the issues related to privacy of medical data in e-prescription. However, not enough studies were conducted to explore and quantify the factors that affect rural patients' compliance with e-prescription, especially from the perspective of Asian developing countries where most of the world's population resides. Therefore, the objective of this study is to explore and assess the factors that affect rural patients' primary compliance with e-prescription in a developing country like Bangladesh.

\section{Methods}

To achieve the research objective, we have selected five sociodemographic factors, that is, age, gender, education, purchase power, and use of cell phone based on existing literature relating to patients' primary compliance with pre-

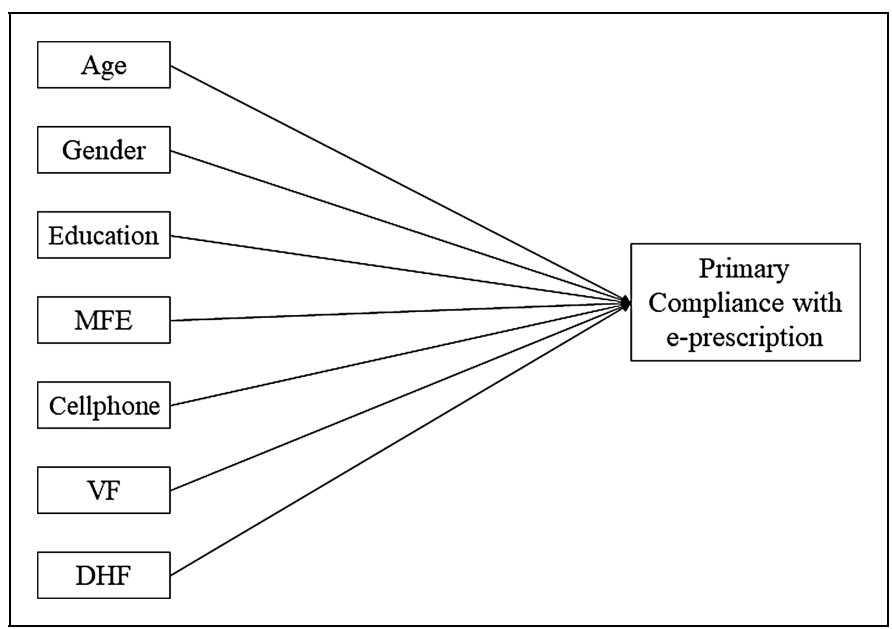

Fig. 2. Research framework. DHF, distance to healthcare facility; MFE, monthly family expenditure; VF, visiting frequency.

scriptions. Several studies ${ }^{2,18-22}$ confirmed the profound impact of patients' sociodemography on their primary compliance with prescribed medication. Patel et al. ${ }^{23}$ found a positive correlation between drug adherence and physician visiting frequency, which motivated us to check whether there is any significant relationship between patients' visiting frequency of PHC and their primary compliance with the prescription. Syed et al. ${ }^{24}$ examined the relationship between medication compliance and distance to pharmacy and prescriber, which reinforced us to add one more variable to our research framework. However, in this study, we have employed a total of seven independent variables to measure their impacts and magnitudes on rural patients' primary compliance with e-prescription, which is shown as our research framework in Figure 2.

From the mentioned framework, keeping the research objective in mind, we have developed the following seven research hypotheses to be tested.

H1: Patients' age has a positive impact on primary compliance with e-prescription.

$\mathrm{H} 2$ : Patients' gender significantly affects their compliance behavior.

H3: Level of education has a positive influence on patients' primary compliance with e-prescription.

H4: Patients' monthly family expenditure affects their primary compliance with e-prescription.

H5: Patients' use of cell phone has a significant impact on their compliance behavior.

H6: Visiting frequency has a positive impact on the patients' primary compliance with e-prescription.

H7: Distance to healthcare facilities has a significant impact on primary compliance with e-prescription. 


\section{HOSSAIN ET AL.}

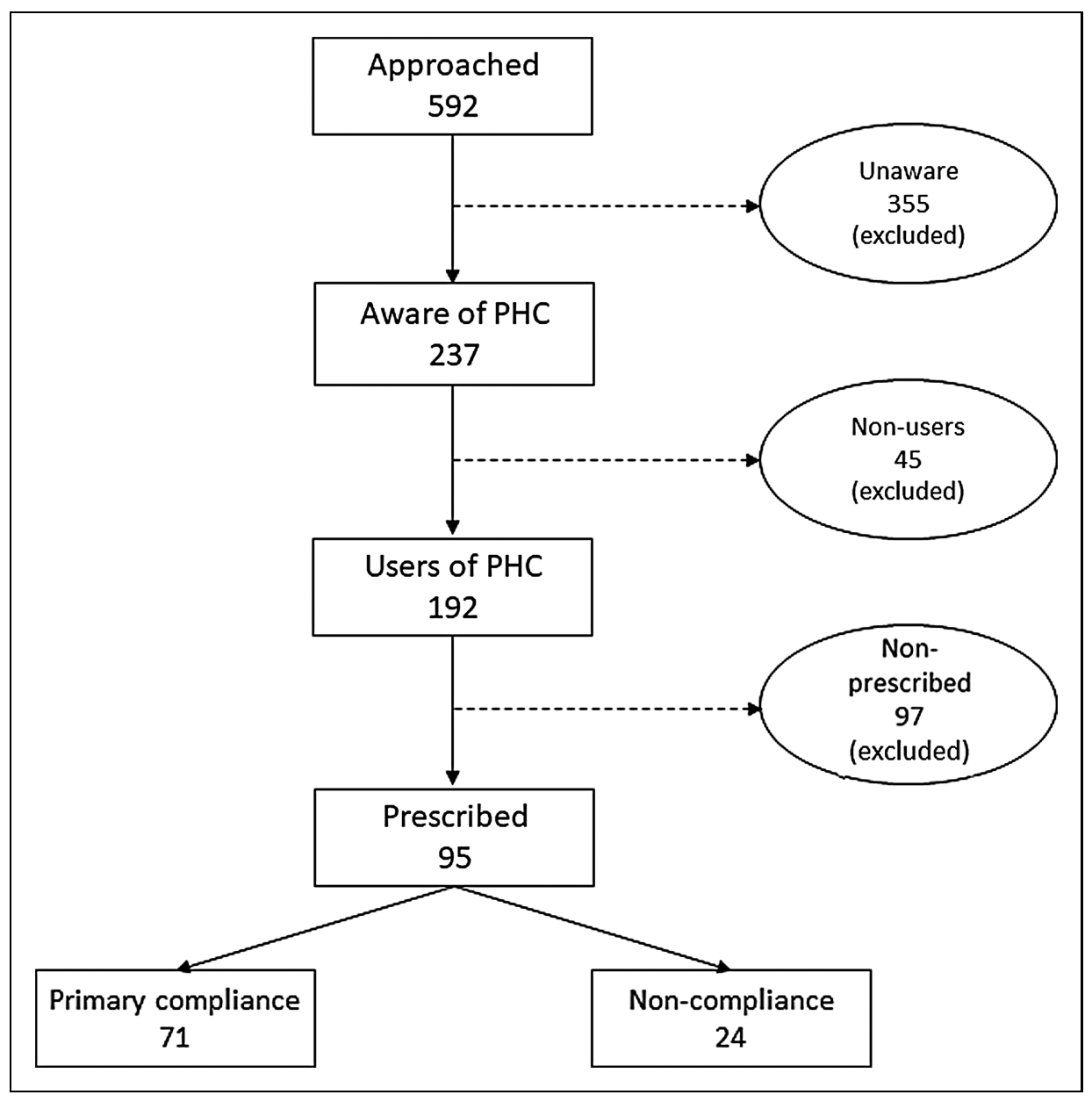

Fig. 3. Steps in sample selection. PHC, Portable Health Clinic.

Since the dependent variable in this study is "compliance with e-prescription" and the response is categorized in either "Yes" or "No," we are dealing with a binary classification problem. Several studies $^{25-27}$ suggested that binary logistic regression fits better in this circumstance. Therefore, we also chose binary logistic regression model to test our research hypotheses. Beleites et al. ${ }^{28}$ suggested a minimum sample size of 75-100 to have a good but not perfect classifier model based on logistic regression. Figueroa et al. ${ }^{29}$ examined a total of 568 supervised learning-based classification models and found models with sample size between 80 and 560 achieved optimum performance. According to Peduzzi et al. ${ }^{30}$ and Kenny, ${ }^{31}$ in behavioral science with multivariate analysis, the sample size should be at least 10 times the number of items (independent variables) in the study. In our study, the model consists of 7 items and the effective sample size is 95 , which is well supported by the studies already mentioned. To reach our targeted sample size, we randomly approached 592 rural respondents in our study area, among whom 355 were found unaware of PHC and were thus

To test the research hypotheses, data were collected through a field survey between June and July 2016 from Bheramara subdistrict of Kushtia, a northwestern district of Bangladesh. A structured questionnaire was developed initially in English, which later was translated into Bengali (the local language of Bangladesh). The survey questionnaire mostly covered the patients' sociodemographic information, their awareness, and usage of e-health, including usage frequency and finally their compliance behavior toward e-prescription. The questionnaire is given in Appendix 1. A pilot study was conducted on 7 randomly selected from $>18$ rural patients to test the understandability of the questionnaire. Their feedback was considered for reviewing the questionnaire. To maintain the right of privacy of the respondents, they have been briefed on the research purpose and were asked whether they want to participate in the survey and allow us to use their responses in our scientific publications. eliminated. Among the rest, 237 respondents who were aware of PHC, 45 found nonusers and were thus eliminated. Therefore, a total of 192 respondents were found who received healthcare services from PHC at least once. However, 95 (49\%) patients out of 192 were reported to receive e-prescription from the remote doctor, thus, in this research, our effective sample size is 95 . The sample selection process is shown in Figure 3.

\section{Results}

\section{RESPONDENTS' DEMOGRAPHY}

Respondents' demographic characteristics are given in Table 2.

The table shows the distribution of dependent variable, that is, patients' compliance with e-prescription, $74.7 \%$ were found compliant who reported collecting all the prescribed medicines, whereas 25.3\% were found noncompliant. The table also shows the descriptive statistics of five independent 


\begin{tabular}{|c|c|c|}
\hline & FREQUENCY & PERCENTAGE \\
\hline \multicolumn{3}{|l|}{ Gender } \\
\hline Male & 62 & 65.0 \\
\hline Female & 33 & 35.0 \\
\hline \multicolumn{3}{|l|}{ Age group } \\
\hline$<30$ & 19 & 20.0 \\
\hline $30-45$ & 43 & 45.5 \\
\hline $46-60$ & 26 & 27.5 \\
\hline$>60$ & 7 & 7.0 \\
\hline \multicolumn{3}{|l|}{ Education } \\
\hline None & 15 & 15.8 \\
\hline Primary & 25 & 26.3 \\
\hline Secondary & 38 & 40.0 \\
\hline College and higher & 17 & 17.9 \\
\hline \multicolumn{3}{|c|}{ Monthly family expenditure (in BDT) } \\
\hline$<10,000$ & 43 & 45.3 \\
\hline $10,001-15,000$ & 40 & 42.1 \\
\hline$>15,000$ & 12 & 12.6 \\
\hline \multicolumn{3}{|l|}{ Use of cell phone } \\
\hline No phone & 16 & 16.8 \\
\hline Feature phone & 65 & 68.4 \\
\hline Smart cell phone & 14 & 14.8 \\
\hline \multicolumn{3}{|c|}{ Compliance with e-prescription } \\
\hline Yes & 71 & 74.7 \\
\hline No & 24 & 25.3 \\
\hline
\end{tabular}

BDT, Bangladeshi taka (the local currency of Bangladesh).

variables, that is, age, gender, education, family expenditure, and use of cell phone. However, we have two more independent variables in this model, that is, PHC visiting frequency and distance to healthcare facility. The median visiting frequency per patient is 2 with a range of $1-10$. The mean distance from patient's place to the nearest conventional healthcare facility is $3.3 \mathrm{~km}$, with a standard deviation of $2.3 \mathrm{~km}$.

\section{CORRELATION AMONG INDEPENDENT VARIABLES}

Pearson correlation analysis is conducted to test whether any multicollinearity exists among independent variables before moving them to the final model, which is given in Table 3.
The matrix shows that no multicollinearity exists among independent variables since all the correlation coefficients are $<0.40$, which was referred as a threshold value by many researchers. $^{32}$

\section{RESULTS OF HYPOTHESES TESTING}

A logistic regression modeling is used to test the hypotheses. A significance level of 0.05 is considered for this model. Decisions regarding hypotheses testing have been made by comparing the variables' $p$-value with models' significance level. Regression coefficient indicates the nature of the relationship between independent and dependent variable, whereas odds ratio explains the magnitude of the effect of independent variables on the dependent variable. The results of hypotheses testing are given in Table 4.

The finding says patients' gender, level of education, PHC visiting frequency, and distance to healthcare facility have significant influences on their primary compliance with eprescription, whereas age, monthly family expenditure, and use of cell phone were found insignificant. Men are 7.5 times more likely to comply with e-prescription than women. Education has a positive correlation with compliance; higher educated patients are 2.5 times more likely to comply. Visiting frequency also has a positive impact, every one additional visit to PHC increases the patients' compliance likelihood by 2.7 times. Finally, distance matters, every $1 \mathrm{~km}$ of additional distance between patients' house and the conventional healthcare facility increases the likelihood of e-prescription compliance by 2.2 times.

\section{MODEL SUMMARY AND GOODNESS-OF-FIT}

Our model has a deviance $R^{2}$ of 0.594 , which means the model explains $59.4 \%$ of the deviance in the response variable. For binary logistic regression, the "Hosmer-Lemeshow" test is a more trustworthy indicator of how well the model fits the data. ${ }^{33}$ In this model, the goodness-of-fit score is 0.99 that is greater than the significance level of 0.05 , which indicates that there is not enough evidence to conclude that the model does not fit the data.

\section{Discussion and Limitations}

A recent study conducted by Raebel et al. on 12,061 hypertension, diabetes, and lipid-disordered patients found that e-prescription reduced the primary noncompliance rate from $22 \%$ to $13 \%$ in comparison with handwritten prescriptions. ${ }^{34}$ Fernando et al. found $12.5 \%$ primary noncompliance with eprescription among 224 emergency department patients. ${ }^{14}$ However, in this study, we found $25.3 \%$ primary noncompliance with e-prescription. This discrepancy exists since 


\section{HOSSAIN ET AL.}

\begin{tabular}{|c|c|c|c|c|c|c|c|}
\hline Age & 1 & & & & & & \\
\hline Gender & 0.32 & 1 & & & & & \\
\hline Education (Edu) & -0.18 & 0.29 & 1 & & & & \\
\hline PVF & -0.03 & 0.31 & 0.14 & 0.27 & 0.19 & 1 & \\
\hline DHF & -0.09 & 0.18 & 0.24 & 0.16 & 0.14 & 0.23 & 1 \\
\hline
\end{tabular}

DHF, distance to healthcare facility; MFE, monthly family expenditure; PVF, PHC visiting frequency.

partner pharmacies have not yet been incorporated into the PHC system. According to a report by the Boston Consulting Group, the electronic transmission of a prescription to a pharmacy increases the possibility of picking up by the patient. It reduces the patient's obligation of providing the prescription to the pharmacy, a problem cited by more than one-third of patients who either forgot to drop it off or had difficulty doing so. ${ }^{35}$ This study found male patients to be more compliant with prescription, which is consistent with some previous studies, ${ }^{22,36-38}$ whereas some studies suggested otherwise. $^{39,40}$ This difference in terms of prescription compliance by gender in rural Bangladesh exists because most of the rural female are unemployed house makers who have less mobility and more financial dependency on their male counterparts. ${ }^{41}$ Several studies ${ }^{42-45}$ found patients with higher educational level have higher propensity to comply with their prescriptions, which resembles our finding too. Innately, it is expected that patients with higher educational level should have better understanding and knowledge about their health, disease, and treatment, and, therefore, be more compliant. $^{19}$

The outcomes of the study were based on patients' selfreporting through a questionnaire survey that might have some response bias. Moreover, the time gap between being prescribed and answering the questionnaire may have allowed for recall bias. The study was conducted on a particular geography, thus, concerns may arise about generalization. Further research, therefore, can be carried out by covering a broader geography and adding a few additional independent variables such as patient-prescriber relationship, patients' trust and attitude toward the system, and distance between patients' house and drugstores to have more comprehensive insights.

\section{Conclusions}

Primary compliance with prescription, in healthcare, is a vital issue since noncompliance causes unexpected delay in health recovery along with financial and social burdens on

\begin{tabular}{|c|c|c|c|c|c|c|}
\hline 1 & Age & -0.390 & 0.6769 & $0.2219-2.0651$ & 0.486 & Not supported \\
\hline 2 & Gender (male) & 2.017 & 7.5134 & $1.0773-52.3988$ & 0.032 & Supported \\
\hline 3 & Education & 0.921 & 2.5120 & $0.9648-6.5399$ & 0.041 & Supported \\
\hline 6 & PVF & 0.994 & 2.7024 & $0.8340-8.7559$ & 0.042 & Supported \\
\hline 7 & Distance to healthcare facility & 0.815 & 2.2595 & $1.1300-4.5183$ & 0.006 & Supported \\
\hline
\end{tabular}

$\mathrm{Cl}$, confidence interval; Coef., regression coefficient; OR, odds ratio. 


\section{E-PRESCRIPTION COMPLIANCE IN RURAL BANGLADESH}

patients. The study found patients' gender, education, visiting frequency to care provider, and distance to healthcare facilities are strongly associated with their compliance behavior, whereas their age, monthly family expenditure, and use of cell phone were found insignificant. The findings of this study are expected to be helpful for e-health service providers to gain a better understanding of the factors that influence their patients to comply with e-prescriptions.

\section{Acknowledgments}

The researchers thank Grameen Communications, Bangladesh, for gathering and sharing data from the experimental field and Toyota Motor Corporation, Japan, for funding this research project.

\section{Disclosure Statement}

No competing financial interests exist.

\section{REFERENCES}

1. Hugtenburg JG, Timmers L, Elders PJM, Vervloet M, van Dijk L. Definitions, variants, and causes of nonadherence with medication: A challenge for tailored interventions. Patient Prefer Adherence 2013;7:675-682.

2. Vrijens $B$, De Geest $S$, Hughes DA, et al. A new taxonomy for describing and defining adherence to medications. Br J Clin Pharmacol 2012;73:691-705.

3. Sackett DL, Snow JC. Compliance in health care. Can Med Assoc J 1979;121: 1495-1496.

4. Lehane $\mathrm{E}, \mathrm{McCarthy} \mathrm{G}$. Intentional and unintentional medication nonadherence: A comprehensive framework for clinical research and practice? A discussion paper. Int J Nurs Stud 2007;44:1468-1477.

5. Ahmed A, Inoue S, Kai E, Nakashima N, Nohara Y. Portable Health Clinic: A pervasive way to serve the unreached community for preventive healthcare. In: Lecture notes in computer science (including subseries lecture notes in artificial intelligence and lecture notes in bioinformatics). Vol 8028 LNCS. Berlin: Springer, 2013:265-274.

6. Ahmed A, Rebeiro-Hargrave A, Nohara $Y$, et al. Portable Health Clinic: A telehealthcare system for unreached communities. In: Lin $Y-L$, Kyung $C-M$, Yasuura H, Liu Y, eds. Smart sensors and systems. Cham: Springer, 2015:447467.

7. Portable Health Clinic (PHC). Available at http://ghealth.gramweb.net (last accessed February 10, 2018).

8. Åstrand B, Montelius E, Petersson G, Ekedahl A. Assessment of ePrescription quality: An observational study at three mail-order pharmacies. BMC Med Inform Decis Mak 2009;9:e8.

9. Kierkegaard P. e-Prescription across Europe. Health Technol (Berl) 2013;3: 205-219.

10. Baseline study of private drug shops in Bangladesh: Findings and recommendations. Arlington, VA: Systems for Improved Access to Pharmaceuticals and Services (SIAPS), 2015.

11. Odukoya OK, Chui MA. e-Prescribing: A focused review and new approach to addressing safety in pharmacies and primary care. Res Soc Adm Pharm 2013; 9:996-1003

12. Jariwala KS, Holmes ER, Banahan BF, McCaffrey DJ. Adoption of and experience with e-prescribing by primary care physicians. Res Soc Adm Pharm 2013;9: 120-128.
13. Kaushal $R$, Kern $L M$, Barrón $Y$, Quaresimo J, Abramson EL. Electronic prescribing improves medication safety in community-based office practices. J Gen Intern Med 2010;25:530-536.

14. Fernando TJ, Nguyen DD, Baraff $\amalg$. Effect of electronically delivered prescriptions on compliance and pharmacy wait time among emergency department patients. Acad Emerg Med 2012;19:102-105.

15. Lapane KL, Dubé C, Schneider KL, Quilliam BJ. Patient perceptions regarding electronic prescriptions: Is the geriatric patient ready? J Am Geriatr Soc 2007; 55:1254-1259.

16. Smith AD. Barriers to accepting e-prescribing in the USA. Int J Health Care Qual Assur 2006;19:158-180.

17. Ateniese G, de Medeiros B. Anonymous e-prescriptions. In: Proceeding of the ACM Workshop on Privacy in the Electronic Society-WPES. Washington, D.C.: 2002:19-31.

18. Fischer MA, Stedman MR, Lii J, et al. Primary medication non-adherence: Analysis of 195,930 electronic prescriptions. J Gen Intern Med 2010;25:284290

19. Lin J, Sklar GE, Oh VM Sen, Li SC. Factors affecting therapeutic compliance: A review from the patient's perspective. Ther Clin Risk Manag 2008;4:269-286.

20. Buck D, Jacoby $A$, Baker GA, Chadwick DW. Factors influencing drug regimes compliance with antiepileptic drug regimes. Seizure 1997;6:87-93.

21. Chesney MA. Factors affecting adherence to antiretroviral therapy. Clin Infect Dis 2000;30(Suppl 2):S171-S176.

22. Sung JCY, Nichol MB, Venturini F, Bailey KL, McCombs JS, Cody M. Factors affecting patient compliance with antihyperlipidemic medications in an $\mathrm{HMO}$ population. Am J Manag Care 1998;4:1421-1430.

23. Patel NC, Crismon ML, Miller AL, Johnsrud MT. Drug adherence: Effects of decreased visit frequency on adherence to clozapine therapy. Pharmacotherapy 2005;25:1242-1247.

24. Syed ST, Sharp LK, Kim Y, et al. Relationship between medication adherence and distance to dispensing pharmacies and prescribers among an urban medicaid population with diabetes mellitus. Pharmacotherapy 2016;36:590597.

25. Davis ப, Offord KP. Logistic regression. J Pers Assess 1997;68:497-507.

26. Cook RD. Binary response variables. Regres Graph 1998;5:78-100.

27. Hair J, Anderson R, Tatham R, Black W. Multivariate data analysis, 5th ed. Upper Saddle River, NJ: Prentice Hall, 1998.

28. Beleites $C$, Neugebauer U, Bocklitz T, Krafft C, Popp J. Sample size planning for classification models. Anal Chim Acta 2013;760:25-33.

29. Figueroa RL, Zeng-Treitler $\mathrm{Q}$, Kandula $\mathrm{S}$, Ngo LH. Predicting sample size required for classification performance. BMC Med Inform Decis Mak 2012;12:8.

30. Peduzzi $P$, Concato J, Kemper $E_{1}$ Holford TR, Feinstem AR. A simulation study of the number of events per variable in logistic regression analysis. J Clin Epidemio/ 1996;49:1373-1379.

31. Kenny DA. Statistics for the social and behavioral sciences. Boston: Little, Brown; 1987

32. Paul RK. Multicollinearity: Causes, effects and remedies. Indian Agric Stat Res Inst 2008;4:2005-2029.

33. Hosmer DW, Lemeshow S. Goodness of fit tests for the multiple logistic regression model. Commun Stat Theory Methods 1980;9:1043-1069.

34. Raebel MA, Ellis JL, Carroll NM, et al. Characteristics of patients with primary non-adherence to medications for hypertension, diabetes, and lipid disorders. $J$ Gen Intern Med 2012;27:57-64.

35. The Boston Consulting Group. Hidden epidemic: finding a cure for unfilled prescriptions and missed dose. Soc Work Mental Health 2003;1:19-34.

36. Frazier PA, Davis-Ali SH, Dahl KE. Correlates of noncompliance among renal transplant recipients. Clin Transplant 1994;8:550-557. 
37. Hertz RP, Unger AN, Lustik MB. Adherence with pharmacotherapy for type 2 diabetes: A retrospective cohort study of adults with employer-sponsored health insurance. Clin Ther 2005;27:1064-1073.

38. Caspard $H$, Chan AK, Walker AM. Compliance with a statin treatment in a usual-care setting: Retrospective database analysis over 3 years after treatment initiation in health maintenance organization enrollees with dyslipidemia. Clin Ther 2005;27:1639-1646.

39. Lindberg $M$, Ekstr M T, Ller MM, Ahlner J. Asthma care and factors affecting medication compliance: The patient's point of view. Int J Qual Health Care 2001;13:375-383

40. Balbay 0 , Annakkaya AN, Arbak P, Bilgin C, Erbas M. Which patients are able to adhere to tuberculosis treatment? A study in a rural area in the Northwest part of Turkey. Jpn J Infect Dis 2005;58:152-158.

41. Sajeda A, Anne PR. Gender inequality within households: The impact of a women's development programme in 36 Bangladeshi villages. Bangladesh Develop Stud 1994;22:121-154.

42. Apter AJ, Reisine ST, Affleck G, Barrows E, ZuWallack RL. Adherence with twicedaily dosing of inhaled steroids: Socioeconomic and health-belief differences. Am J Respir Crit Care Med 1998;157:1810-1817.

43. Okuno J, Yanagi $H$, Tomura S. Is cognitive impairment a risk factor for poor compliance among Japanese elderly in the community? Eur J Clin Pharmacol $2001 ; 57: 589-594$

\section{Appendix 1}

\section{Survey Questionnaire: For Exploring the Factors Affecting Primary Compliance with e-Prescription}

1. Respondent's age: []

2. Respondent's gender:
(a) Male
(b) Female

3. Level of education:
(a) None
(b) Primary
(c) Secondary
(d) College and higher

4. Monthly family expenditure (in BDT):
(a) Less than 10,000
(b) $10,001-15,000$
(c) More than 15000

5. Do you have a mobile phone?
(a) Yes
(b) No
(If the answer is "Yes")

5.1. What kind of phone you have?
(a) Feature phone
(b) Smartphone
(c) Both

6. What is the distance between your house and the nearest traditional healthcare center such as hospital or clinic?

Ans.: $\mathrm{km}$.
44. Ghods AJ, Nasrollahzadeh D. Noncompliance with immunnosuppressive medications after renal transplantation. Exp Clin Transp/ 2003;1:39-47.

45. Yavuz $A$, Tuncer $M$, Erdoğan 0 , et al. Is there any effect of compliance on clinical parameters of renal transplant recipients? Transplant Proc 2004;36: 120-121.

Address correspondence to:

Nazmul Hossain, MBA

Department of Advanced Information Technology

Kyushu University

Ito Campus, 744 Moto'oka

Nishi-ku Fukuoka 819-0395

Japan

E-mail: nazmul@f.ait.kyushu-u.ac.jp; nhossain01@du.ac.bd

Received: March 23, 2018

Revised: May 12, 2018

Accepted: May 12, 2018

Online Publication Date: June 8, 2018

7. Do you think ICT (mobile phone, laptop computer, internet network) can be used to obtain healthcare services (health checkup, consulting with doctors, obtaining prescription, etc.)?
(a) Yes

(b) No

8. Have you ever seen any promotional campaign (poster, leaflet, announcement, etc.) of Portable Health Clinic (PHC) in your area?
(a) Yes
(b) No

9. Have you ever received any healthcare service from PHC?
(a) No
(b) Yes
(If the answer is "Yes")

9.1. How many times have you visited PHC?
(a) Only once
(b) More than once
(c) Mention whether you remember (.........) times

10. Have you ever received any e-prescription from PHC?

(a) No

(b) Yes

(If the answer is "Yes")

10.1. What did you do after getting that prescription?

(a) I bought all the drugs according to the prescription

(b) I bought some of the drugs but not all

(c) I didn't buy any drug and waited for natural recovery 